\title{
ANALISA DAMPAK LALU LINTAS TERHADAP RENCANA PENGEMBANGAN KAWASAN PERKANTORAN KOTA MARTAPURA
}

\author{
$\underline{\text { Bagus Ridhani }}{ }^{1}$ \\ ${ }^{1}$ PT. Geo Inti Perkasa, Banjarbaru
}

\begin{abstract}
ABSTRAK
Pengembangan kawasan perkantoran di Kota Martapura berdasarkan masterplan RTBL Kabupaten Banjar memiliki luas lahan sebesar 103,5 Ha dengan luas total $90.270 \mathrm{~m} 2$ untuk kantor-kantor pemerintahan dan dinas. Diduga setelah kawasan perkantoran selesai dibangun dan mulai beroperasi akan memberikan dampak yang cukup besar terhadap jaringan jalan yang berada di sekitar pengembangan kawasan tersebut. Penelitian ini bertujuan untuk memprediksi besarnya bangkitan/tarikan pergerakan atau perjalanan yang terjadi akibat kawasan perkantoran yang telah beroperasi, menganalisis kinerja lalu lintas pada jaringan jalan yang diperkirakan akan terpengaruh oleh kawasan perkantoran setelah beroperasi, menganalisis dampak yang ditimbulkan oleh beroperasinya kawasan perkantoran dan memberikan solusi penanganan yang tepat untuk mempertahankan kelancaran arus lalu lintas di sekitar kawasan perkantoran. Analisis data dilakukan dengan mengumpulkan data arus lalu lintas dan membuat Matrik Asal Tujuan (MAT) dengan menggunakan metode Detroit untuk melakukan prediksi pada kondisi pasca-konstruksi, 5 tahun dan 10 tahun pasca konstruksi pada ruas jalan yang ditinjau serta menghitung tingkat pelayanan pada masing-masing tahun tinjauan sesuai dengan skenario penanganan yang telah ditentukan. Besar bangkitan/pergerakan lalu lintas yang terjadi adalah sebesar 788 kendaraan atau 462 SMP/Jam. Pada kondisi eksisting tingkat pelayanan terburuk D yaitu jalan Sekumpul (Jl. A. Yani), jalan Sekumpul Ujung (Indrasari) dan Pasar Martapura (Jl. Barakat). Prakiraan dampak lalu lintas yang ditimbulkan adalah kenaikan DS yang berkisar antara 9,48\% hingga 53,53\%. Rekomendasi penanganan yang dapat diberikan adalah Skenario 3 dengan membuat akses exit/entry pada ruas jalan Alkah sehingga pertumbuhan volume lalu lintas yang terjadi pada ruas jalan Sekumpul menjadi $12 \%$ hingga $56 \%$.
\end{abstract}

Kata Kunci: analisa dampak lalu lintas, matrik asal tujuan, derajat kejenuhan, tingkat pelayanan.

\section{PENDAHULUAN}

Kota Martapura merupakan ibukota dari Kabupaten Banjar di Provinsi Kalimantan Selatan dengan luas wilayah $42,03 \mathrm{Km} 2$ dan jumlah penduduk sebanyak 108.162 jiwa. Sebagai ibukota kabupaten, Kota Martapura mengalami perkembangan ekonomi yang cukup pesat. Sebagai ibukota Kabupaten Banjar, segala kegiatan pemerintahan berpusat Kota Martapura. Agar segala kegiatan pemerintahan dapat berjalan dengan lancar dan terintegrasi dengan baik maka semua kantor-kantor pemerintahan berada pada kawasan yang diperuntukan sebagai kawasan perkantoran.

Berdasarkan masterplan Rencana Tata Bangunan dan Lingkungan (RTBL)

Correspondence: Bagus Ridhani

Email:bagusridhani@gmail.com
Kabupaten Banjar, kawasan yang akan dikembangkan yaitu kawasan perdagangan dan jasa, kawasan olahraga, kawasan perkantoran swasta dan kawasan perkantoran pemerintah Kabupaten Banjar. Kawasan perkantoran pemerintah Kota Martapura berada di Kelurahan Sungai Besar/Ulin Kota Banjarbaru. Dari gambar masterplan RTBL Kabupaten Banjar pengembangan kawasan perkantoran pemerintah tersebut adalah seluas 103,5 Ha dengan luas total $90.270 \mathrm{~m} 2$ untuk kantor-kantor pemerintahan dan dinas. Kantor-kantor yang akan dibangun berdasarkan masterplan RTBL Kabupaten Banjar yaitu Kantor Utama (Kantor Bupati, Sekda, DPRD, Pengadilan Negeri, Kejaksaan dan Polres), Perkantoran Badan (BKD, BAPPEDA, Lingkungan Hidup, BAKESBANGPOL, BPP, Perlindungan Anak \& KB, Badan Pelaksana Penyuluh, Badan Pelayanan Perijinan Terpadu, Badan 
Pemberdayaan Masyarakat \& Pemerintahan Desa, Badan Penanggulangan Bencana Daerah dan Bantuan Satpol PP), Perkantoran Dinas (Dinas Pertanian, Perkebunan \& Peternakan, Dinas Perikanan \& Kelautan, Dinas Pendidikan, Dinas Perindustrian \& Perdagangan, Dinas Pendapatan Pengelolaan Keuangan Aset Daerah, Dinas Kependudukan \& Catatan Sipil, Dinas Kesehatan, Dinas Pertambangan \& Energi, Dinas Kehutanan, Dinas Perhubungan, Komunikasi \& Informasi, Dinas Tenaga Kerja \& Transmigrasi, Dinas Sosial, Dinas Bina Marga \& Sumberdaya Air, Dinas Perumahan \& Permukiman, Dinas BudPar Pemuda \& Olahraga, Dinas Kop. Usaha Mikro Kecil \& Menengah dan Inspektorat).

Dengan dibangunnya kawasan perkantoran tersebut, diduga akan menimbulkan tarikan lalu lintas yang sangat besar pada jaringan jalan yang berada di sekitar pengembangan kawasan tersebut. Dampak lalu lintas yang dapat ditimbulkan diantaranya adalah memberikan tekanan yang cukup besar pada prasarana jalan yang ada di sekitar kawasan pengembangan sehingga tidak mampu lagi untuk melayani dan menampung beban lalu lintas akibat beroperasinya kawasan perkantoran tersebut.

Hal ini didukung oleh penelitian Zuhdi (2017) tentang Analisis Dampak Lalu Lintas Akibat Pembangunan Best Western Star Hotel Dan Star Apartement Semarang Terhadap Kinerja Jaringan Jalan Sekitar. Dari hasil analisa setelah adanya tarikan perjalanan akibat operasionalnya Best Western Star Hotel dan Star Apartement Semarang kinerja ruas jalan menjadi menurun akibat pertambahan volume lalu lintas. Kinerja ruas Jalan Sriwijaya dan Jalan Lampersari tidak mampu melayani arus lalu lintas yang terjadi, nilai DS (Degree of Saturation) Jalan Sriwijaya menjadi 1,72 dan nilai DS Jalan Lampersari menjadi 0,98.

Dari kondisi tersebut di atas maka perlu dilakukan analisis dampak lalu lintas terhadap jaringan jalan di sekitar kawasan pengembangan perkantoran untuk melihat bagaimana dampak yang akan ditimbulkan dari pengembangan tersebut. Berdasarkan Peraturan Daerah Kabupaten Banjar No. 2 Tahun 2015 tentang Analisis Dampak Lalu lintas di Jalan wajib dilakukan analisis dampak lalu lintas untuk setiap pembangunan pusat-pusat kegiatan ataupun pengembangan kawasan khususnya yang diperkirakan akan memberikan dampak cukup besar terhadap sistem jaringan jalan di sekitarnya dan memberikan usulan penanganan dampak lalu lintas yang terjadi untuk mempertahankan kelancaran arus lalu lintas di kawasan tersebut.

\section{METODE PENELITIAN}

Penelitian ini dilakukan dengan cara melakukan survey pergerakan lalu lintas pada kondisi eksisting dan kemudian dilakukan peramalan berdasarkan karakteristik pergerakan lalu lintas eksisting. Data-data primer yang diperlukan didapatkan dengan cara pengumpulan data lalu lintas, survey geometrik, serta wawancara. Sedangkan data-data primer yang diperlukan adalah masterplan RTBL (Rencana Tata Bangunan dan Lingkungan) Kabupaten Banjar dan data kependudukan untuk mendapatkan tingkat pertumbuhan penduduk.

Data lalu lintas yang didapatkan digunakan untuk membuat matriks asal tujuan (MAT) berdasarkan hasil survey wawancara untuk digunakan sebagai MAT dasar. MAT dasar yang didapatkan kemudian digunakan untuk memprediksi pergerakan lalu lintas yang terjadi pada masing-masing tahun tinjauan (eksisting, tahun ke-1 pasca kanstruksi, tahun ke-5 pasca konstruksi dan tahun ke-10 pasca konstruksi). Secara lengkap Bagan alir penelitian dapat dilihat pada Gambar 1. 
Bagus Ridhani

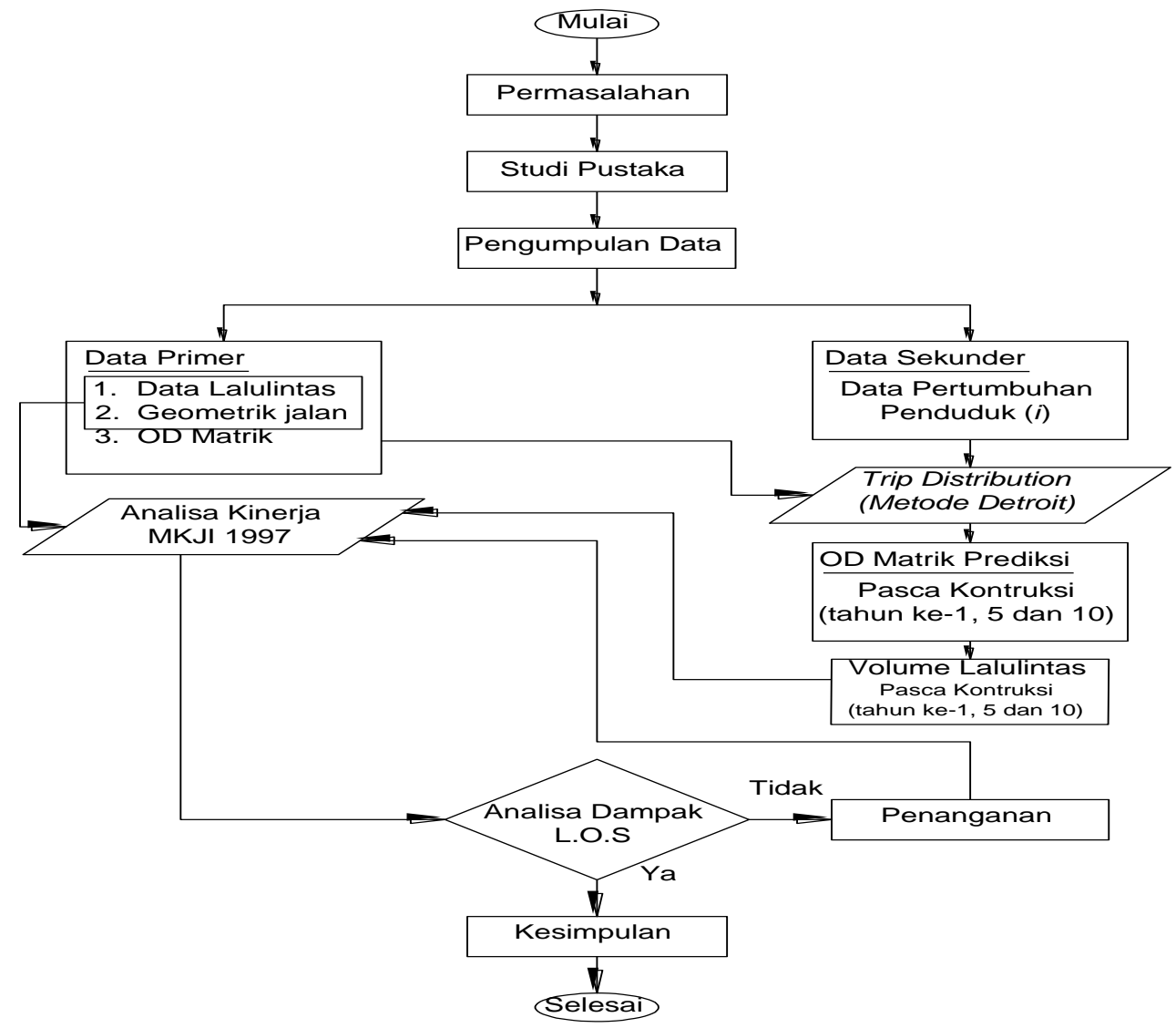

Gambar 1. Bagan Alir Penelitian

Tahapan peramalan atau forcasting lalu lintas digunakan metode Detroit untuk mendapatkan data lalu lintas pada tahun ke-1 pasca kanstruksi, tahun ke-5 pasca konstruksi dan tahun ke-10 pasca konstruksi. Bagan alir perhitungan forcasting data lalu lintas dapat dilihat pada Gambar 2.

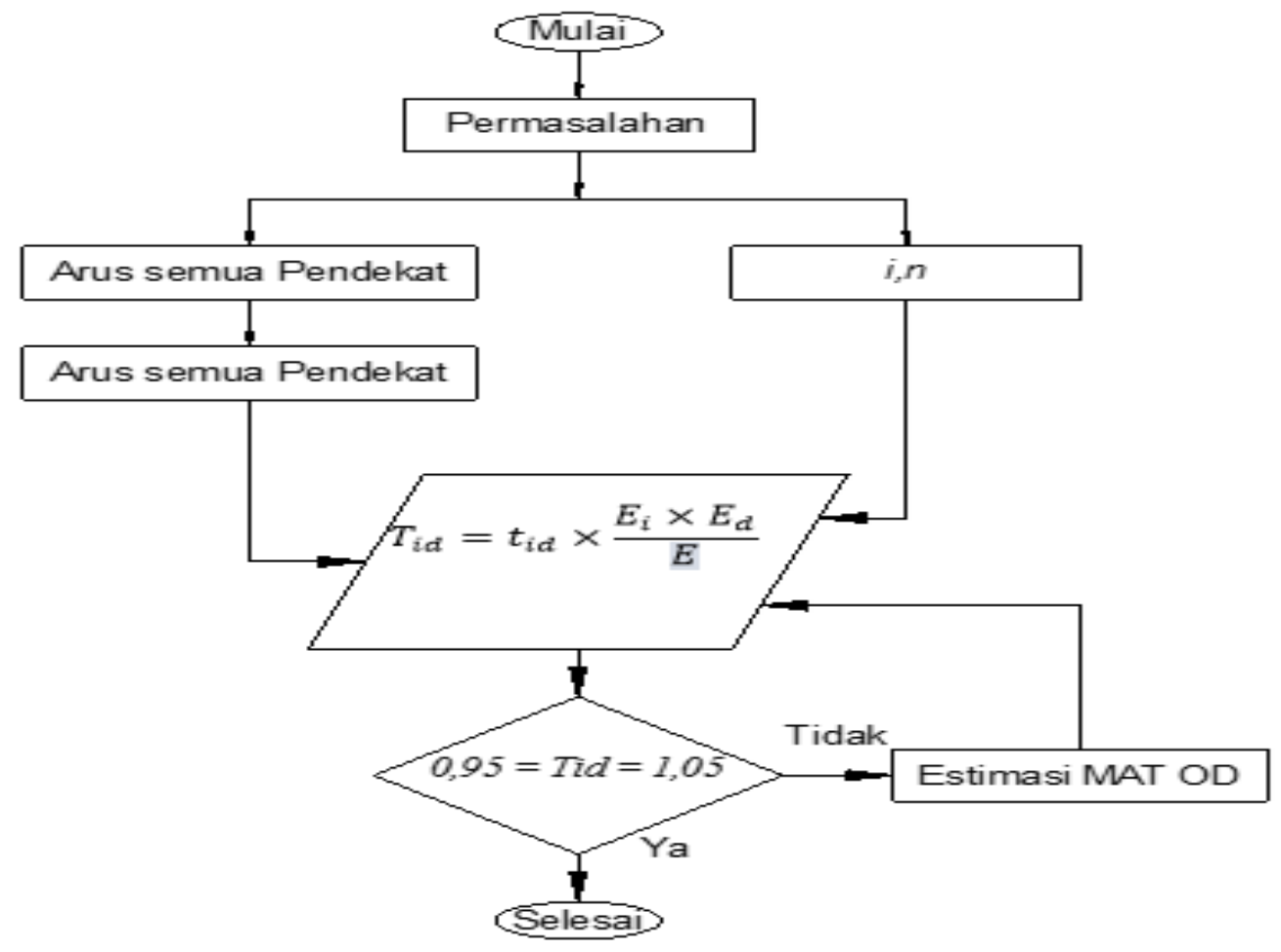

Gambar 2. Bagan Alir Perhitungan Forcasting Data Lalu Lintas 
Lokasi pengambilan data lalu lintas dilakukan disekitar kawasan pengembangan perkantoran yakni pada simpang empat Sekumpul (Jl. A. Yani Km. 39,00), simpang tiga Sekumpul-Indrasari, simpang tiga CBSTanjung Rema dan simpang tiga Sei. Ulin (Jl. P. M. Noor). Gambaran lengkap lokasi titik survey dapat dilihat pada Gambar 3.

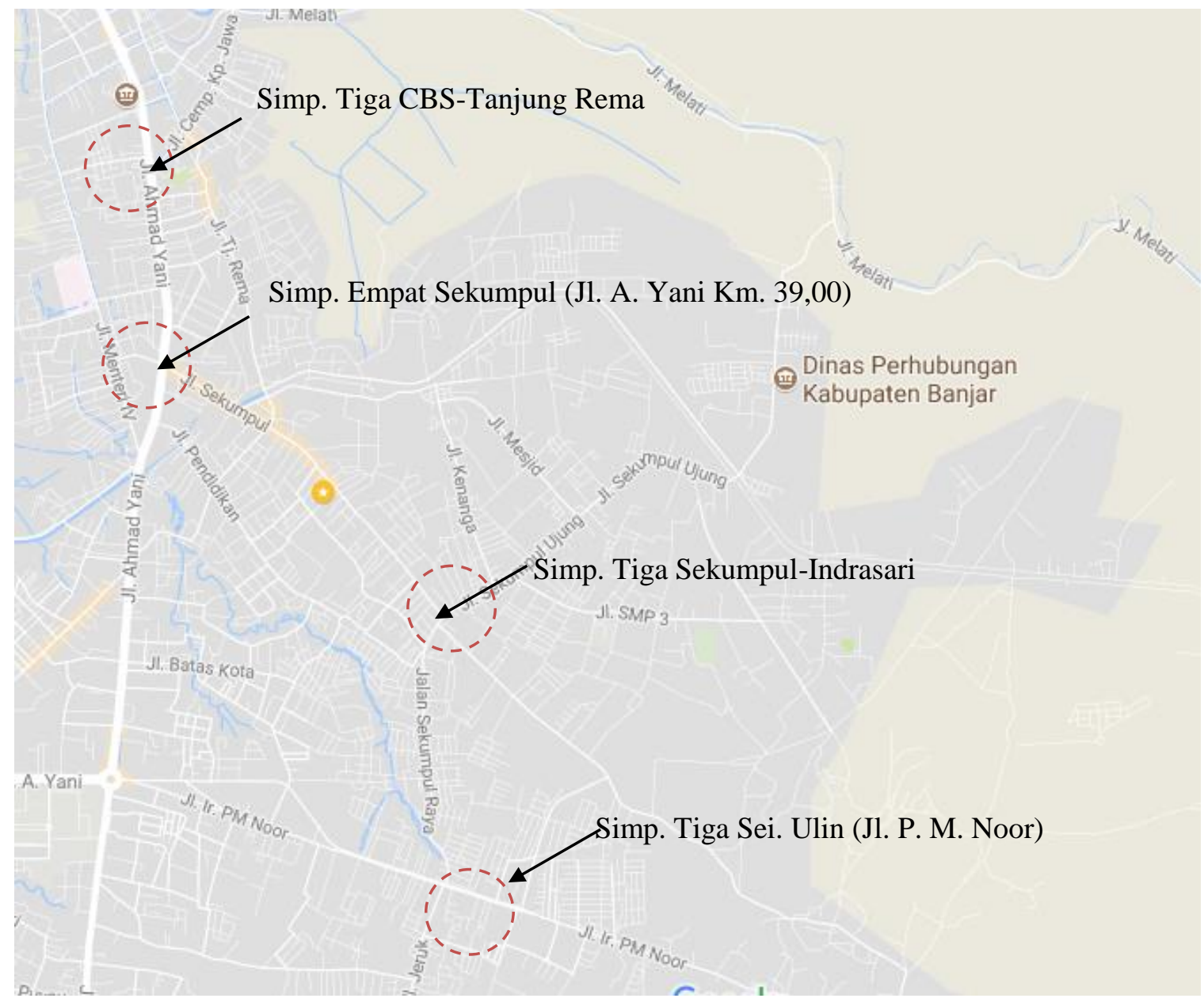

Gambar 3. Lokasi Titik Survey

Analisis kinerja ruas jalan pada masing-masing tahun tinjauan diberikan penyesuaian terhadap skenario-skenario penanganan yang telah diberikan sebagai penentuan skenario penanganan yang akan direkomendasikan. Skenario dengan pertumbuhan lalu lintas terendah akan direkomendasikan dengan memerhatikan pusat kegiatan eksisting yang sudah ada terlebih dahulu agar tidak terganggu

\section{HASIL DAN PEMBAHASAN}

Analisa kinerja jaringan jalan dilakukan untuk mengetahui tingkat pelayanan, yang dimaksudkan untuk melihat apakah suatu ruas jalan atau persimpangan masih mampu memberikan pelayanan yang memadai bagi para pengguna jalan. Kinerja jaringan jalan dapat dilihat dari nilai kapasitas ruas jalan $(C)$ dan $Q / C$ ratio digunakan untuk melihat Indikator Tingkat Pelayanan (ITP) yang berfungsi sebagai evaluasi terhadap kinerja lalu lintas. Kapasitas ruas jalan sangat tergantung dengan kondisi jalan baik lebar, tipe, hambatan dan ukuran kota. Prediksi kinerja ruas jalan yang ditinjau pada jam puncak dapat dilihat pada Tabel 1. 
Tabel 1. Prediksi Kinerja Ruas Jalan Yang Ditinjau pada Jam Puncak

\begin{tabular}{|c|c|c|c|c|c|c|c|c|c|c|}
\hline \multirow[t]{2}{*}{ No } & \multirow[t]{2}{*}{ Ruas Jalan } & \multirow[t]{2}{*}{ Kode } & \multicolumn{2}{|c|}{ Eksisting } & \multicolumn{2}{|c|}{$\begin{array}{c}\text { Pasca } \\
\text { Konstruksi }\end{array}$} & \multicolumn{2}{|c|}{$\begin{array}{c}5 \text { Tahun } \\
\text { Pasca } \\
\text { Konstruksi }\end{array}$} & \multicolumn{2}{|c|}{$\begin{array}{c}10 \text { Tahun } \\
\text { Pasca } \\
\text { Konstruksi }\end{array}$} \\
\hline & & & DS & ITP & DS & ITP & DS & ITP & DS & ITP \\
\hline \multirow{2}{*}{1} & \multirow{2}{*}{$\begin{array}{l}\text { Jl. A. Yani Km. } 39 \\
\text { (Banjarbaru) }\end{array}$} & AY39(BJB) & 0,64 & B & 0,71 & $\mathrm{C}$ & 0,83 & $\mathrm{D}$ & 0,99 & E \\
\hline & & \multicolumn{2}{|c|}{ Peningkatan DS (\%) } & \multicolumn{2}{|c|}{9,51} & \multicolumn{2}{|c|}{28,67} & \multicolumn{2}{|c|}{53,40} & \\
\hline \multirow{2}{*}{2} & \multirow{2}{*}{$\begin{array}{l}\text { Jl. A. Yani Km. } 39 \\
\text { (Martapura) }\end{array}$} & AY39(MTP) & 0,59 & A & 0,65 & B & 0,76 & $\mathrm{C}$ & 0,91 & $\mathrm{E}$ \\
\hline & & \multicolumn{2}{|c|}{ Peningkatan DS (\%) } & \multicolumn{2}{|c|}{9,48} & \multicolumn{2}{|c|}{28,66} & \multicolumn{2}{|c|}{53,41} & \\
\hline \multirow{2}{*}{3} & \multirow{2}{*}{$\begin{array}{l}\text { Pusat Perbelanjaan } \\
\text { Sekumpul }\end{array}$} & PPS & 0,24 & A & 0,26 & A & 0,31 & A & 0,37 & A \\
\hline & & \multicolumn{2}{|c|}{ Peningkatan DS (\%) } & \multicolumn{2}{|c|}{9,48} & \multicolumn{2}{|c|}{28,68} & \multicolumn{2}{|c|}{53,49} & \\
\hline \multirow{2}{*}{4} & \multirow{2}{*}{ Jl. Sekumpul (Jl. A. Yani) } & SKP(AY) & 0,85 & $\mathrm{D}$ & 0,93 & $\mathrm{E}$ & 1,09 & $\mathrm{~F}$ & 1,30 & $\mathrm{~F}$ \\
\hline & & \multicolumn{2}{|c|}{ Peningkatan DS (\%) } & \multicolumn{2}{|c|}{9,48} & & & & & \\
\hline 5 & I) Solumnul (Indrociri) & SKP(IDR) & 0,61 & $\mathrm{~B}$ & 0,67 & B & 0,78 & $\mathrm{C}$ & 0,93 & $\mathrm{E}$ \\
\hline 3 & J. seкumpur (murasar1) & Peningkatan & $(\%)$ & & & & & & & \\
\hline 6 & Jl. Tanjung Rema (Jl. & TJR(SKP) & 0,56 & A & 0,61 & B & 0,72 & $\mathrm{C}$ & 0,85 & $\mathrm{D}$ \\
\hline 0 & Sekumpul) & Peningkatan & $(\%)$ & & & & & & & \\
\hline 7 & Jl. Tanjung Rema (Pasar & $\mathrm{TJR}(\mathrm{PM})$ & 0,73 & $\mathrm{C}$ & 0,80 & $\mathrm{D}$ & 0,94 & $\mathrm{E}$ & 1,12 & $\mathrm{~F}$ \\
\hline 1 & Martapura) & Peningkatan & $(\%)$ & & & & & & & \\
\hline 8 & Jl. Sekumpul Ujung & SKU(IDR) & 0,82 & $\mathrm{D}$ & 0,89 & $\mathrm{D}$ & 1,05 & $\mathrm{~F}$ & 1,25 & $\mathrm{~F}$ \\
\hline 0 & (Indrasari) & Peningkatan & $(\%)$ & & & & & & & \\
\hline 0 & Jl. Sekumpul Ujung (Sei. & SKU(SUL) & 0,61 & B & 0,66 & B & 0,78 & $\mathrm{C}$ & 0,93 & $\mathrm{E}$ \\
\hline 9 & Ulin) & Peningkatan & $(\%)$ & & & & & & & \\
\hline 10 & Pasar Martapura (Jl. & $\mathrm{PM}(\mathrm{SKR})$ & 0,80 & $\mathrm{D}$ & 0,88 & $\mathrm{D}$ & 1,03 & $\mathrm{~F}$ & 1,23 & $\mathrm{~F}$ \\
\hline 10 & Sukaramai) & Peningkatan & $(\%)$ & & & & & & & \\
\hline 11 & I1 Dorglot 2 ( & BRT & 0,45 & $\mathrm{~A}$ & 0,50 & A & 0,58 & A & 0,69 & $\mathrm{~B}$ \\
\hline 11 & J. Barakat & Peningkatan & $(\%)$ & & & & & & & \\
\hline 12 & J1. P. M. Noor & $\mathrm{PMN}(\mathrm{BJB})$ & 0,14 & A & 0,15 & A & 0,18 & A & 0,21 & A \\
\hline 12 & (Banjarbaru) & Peningkatan & $(\%)$ & & & & & & & \\
\hline 13 & Jl. P. M. Noor (Karang & $\mathrm{PMN}(\mathrm{KRT})$ & 0,13 & A & 0,14 & A & 0,16 & A & 0,19 & A \\
\hline 13 & Intan) & Peningkatan & $(\%)$ & & & & & & & \\
\hline 14 & Il $\Delta 1 \mathrm{kah}$ & ALK & 0,35 & A & 0,38 & A & 0,45 & A & 0,54 & A \\
\hline & & Peningkatan & $(\%)$ & & & & & & & \\
\hline
\end{tabular}

Pada Tabel 1 pada kondisi dimana kawasan perkantoran sebelum beroperasi diprediksi bahwa nilai $D S$ masing-masing ruas jalan yang ditinjau adalah dari kondisi eksisting dan masing-masing tahun tinjauan adalah berkisar antara 9,48\% hingga 53,53\%. Peningkatan nilai $D S$ yang sangat besar memberikan dampak terhadap ruas jalan yang dilayani adalah ruas jalan Sekumpul (Jl. A. Yani). Terlihat bahwa $D S$ ruas jalan Sekumpul (Jl. A. Yani) pada kondisi eksisting adalah sebesar 0,85 (ITP D) kemudian pada kondisi pasca konstruksi nilai DS 0,93 (ITP E), pada kondisi 5 tahun pasca konstruksi nilai $D S$ 1,09 (ITP F) dan terakhir pada kondisi 10 tahun pasca konstruksi nilai DS 1,30 (ITP F).
Berdasarkan "Pedoman Analisis Dampak Lalu Lintas Jalan Akibat Pengembangan Kawasan di Perkotaan", kriteria dampak lalu lintas pada ruas jalan yang ditinjau dan membutuhkan penanganan adalah apabila nilai $D S$ dari tiap kondisi ruas jalan tersebut bernilai $\geq 0,75$. Dibuat lah beberapa skenario yang bertujuan untuk melakukan simulasi yang terjadi pada ruasruas jalan yang ditinjau pada masing-masing tahun tinjauan bagaimana pengaruhnya terhadap jumlah volume arus lalu lintas berdasarkan perlakuan yang diberikan pada masing-masing skenario sehingga dapat dipilih skenario mana yang dapat direkomendasikan untuk menangani akibat yang timbul setelah kawasan perkantoran beroperasi. 
Pada skenario 1 akan disimulasikan bahwa kawasan perkantoran akan memiliki akses masuk dan keluar (entry/exit) pada ruas jalan Sekumpul (Jl. A. Yani) dan jalan Sekumpul Ujung (Indrasari). Kedua ruas jalan tersebut digunakan sebagai jalan entry/exit kawasan perkantoran dikarenakan perkerasan yang digunakan adalah perkerasan aspal dimana kedua ruas jalan tersebut sudah terhubung menuju rencana pengembangan kawasan perkantoran. Jarak tempuh dari titik entry/exit adalah sekitar 4,9 $\mathrm{Km}$ dengan waktu tempuh selama \pm 13 menit. Entry/Exit kawasan perkantoran skenario 1 dapat dilihat pada Gambar 4.

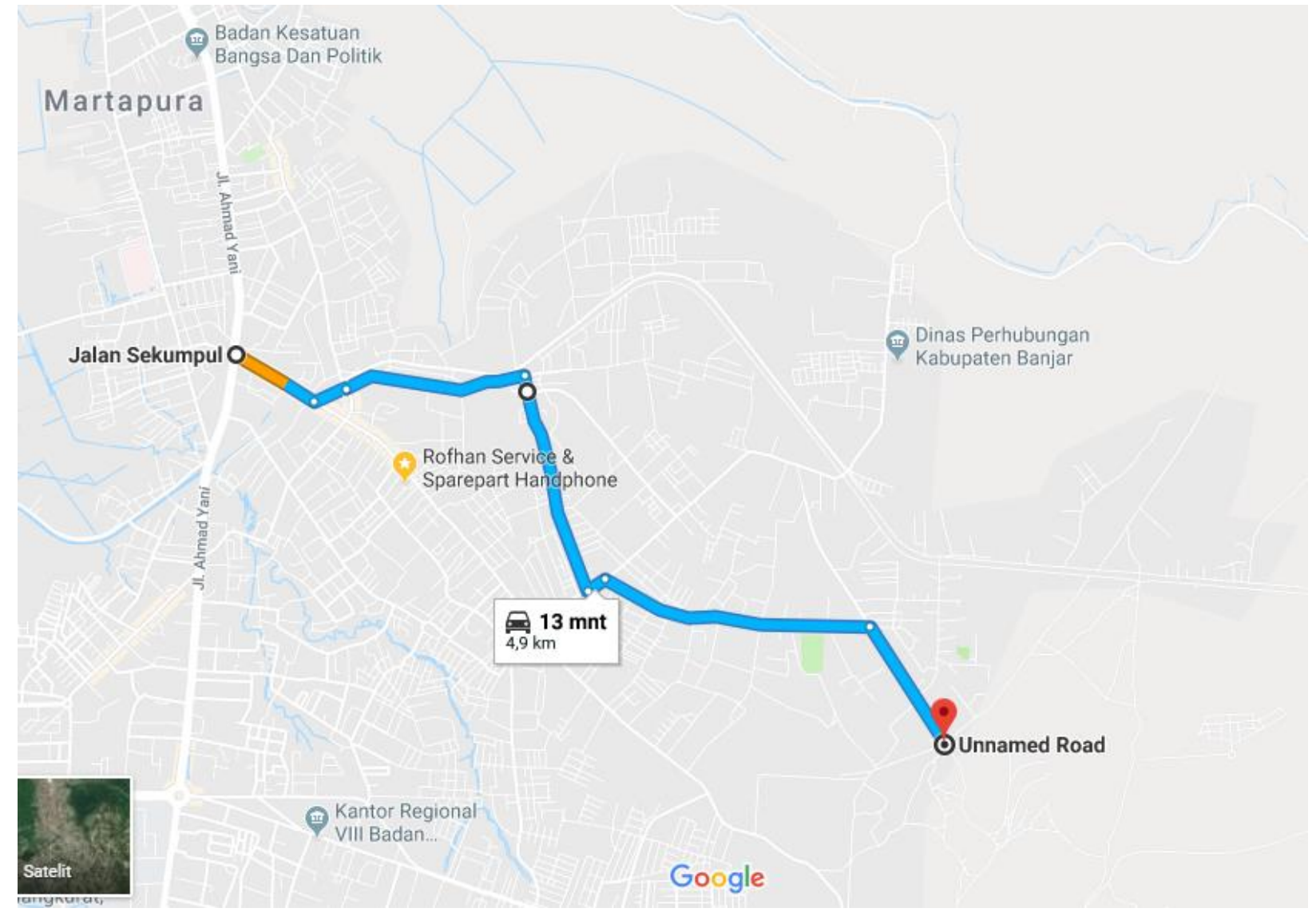

Gambar 4. Entry/Exit Kawasan Perkantoran Skenario 1

Asumsi pergerakan penambahan arus menuju kawasan perkantoran yang digunakan yaitu apabila daerah asal berada di Banjarbaru, Banjarmasin, Cindai Alus, Gambut, Sei. Sipai, Sei. Paring, Martapura, Sekumpul dan Tanjung Rema akan melewati ruas jalan Sekumpul (Jl. A. Yani) dan ruas Jalan Sekumpul Ujung (Indrasari). Apabila daerah asal berada di Indrasari dan Sei. Ulin akan melewati ruas jalan Sekumpul Ujung (Indrasari). Asumsi pergerakan menuju kawasan perkantoran yang terjadi adalah pada waktu jam 08.00 WITA.

Pada skenario 2 akan disimulasikan bahwa kawasan perkantoran akan memiliki akses masuk dan keluar (entry/exit) pada ruas jalan Barakat dan Pasar Martapura (Jl. Sukaramai). Kedua ruas jalan tersebut digunakan sebagai jalan entry/exit kawasan perkantoran dikarenakan perkerasan kedua ruas jalan tersebut sudah terhubung menuju rencana pengembangan kawasan perkantoran melalui jalan Melati agar arus lalu lintas tidak terpusat di ruas jalan Sekumpul. Jarak tempuh dari titik entry/exit adalah sekitar 7,7 $\mathrm{Km}$ dengan waktu tempuh selama \pm 23 menit. Entry/Exit kawasan perkantoran scenario 2 dapat dilihat pada Gambar 5. 


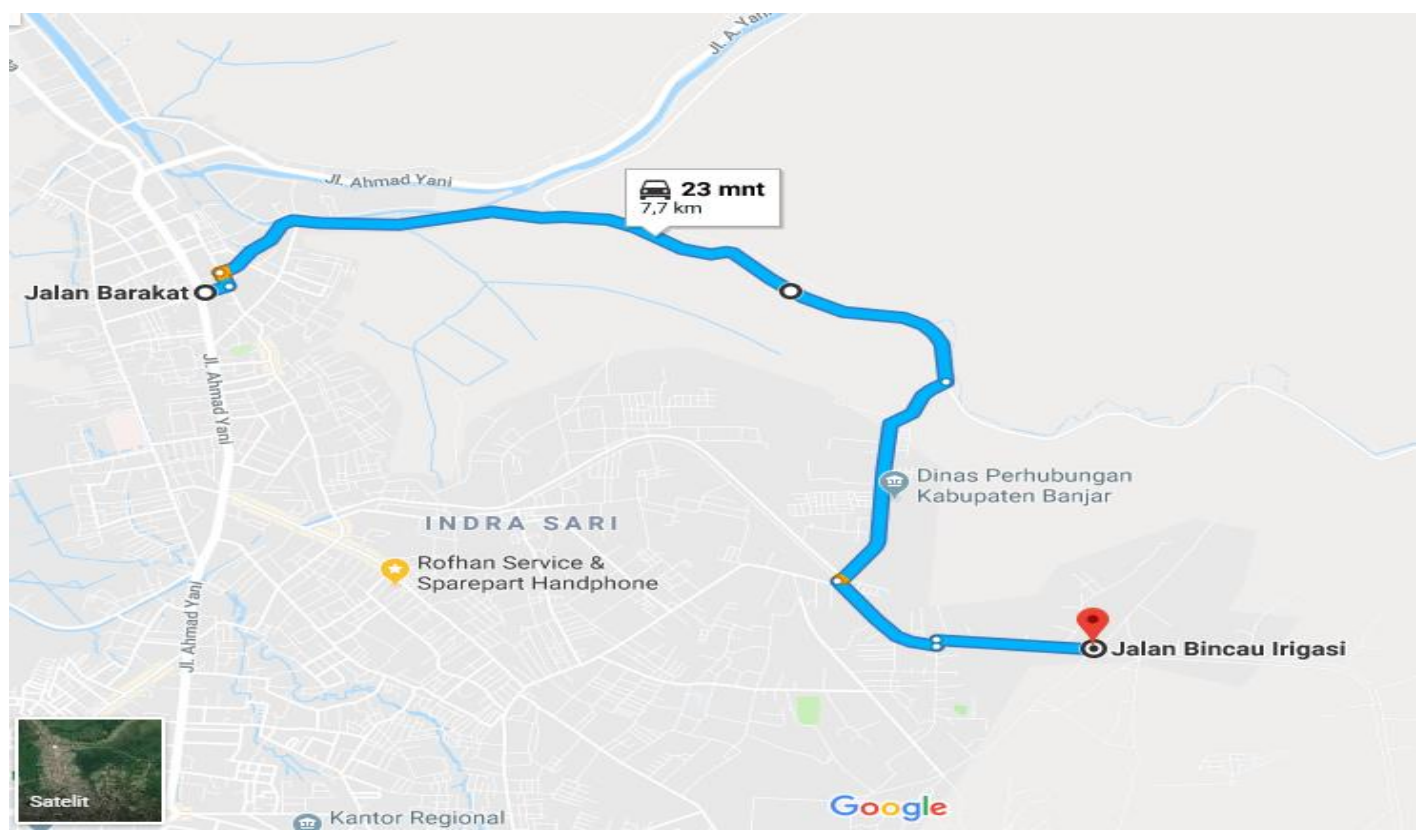

Gambar 5. Entry/Exit Kawasan Perkantoran Skenario 2

Asumsi pergerakan penambahan arus menuju kawasan perkantoran yang digunakan yaitu apabila daerah asal berada di Banjarbaru, Banjarmasin, Cindai Alus, Gambut, Sei. Sipai dan Sei. Paring akan melewati ruas jalan Pasar Martapura (Jl. Sukaramai). Apabila daerah asal berada di Martapura, Sekumpul, Tanjung Rema, Indrasari dan Sei. Ulin akan melewati ruas jalan Sekumpul Ujung (Indrasari). Asumsi pergerakan menuju kawasan perkantoran yang terjadi adalah pada waktu jam 08.00 WITA.

Pada skenario 3 akan disimulasikan bahwa kawasan perkantoran akan memiliki akses masuk dan keluar (entry/exit) pada ruas jalan Alkah. Ruas jalan tersebut digunakan sebagai jalan entry/exit kawasan perkantoran dikarenakan ruas jalan tersebut tidak berada di kawasan padat penduduk serta kegiatan ekonomi seperti pada ruas jalan Sekumpul dan Pasar Martapura (Jl. Sukaramai) sehingga arus menuju kawasan perkantoran tidak mengganggu pusat kegiatan yang telah ada lebih dahulu. Jarak tempuh dari titik entry/exit adalah sekitar 2,7 $\mathrm{Km}$ dengan waktu tempuh selama \pm 8 menit. Entry/Exit kawasan perkantoran skenario 3 dapat dilihat pada Gambar 6.

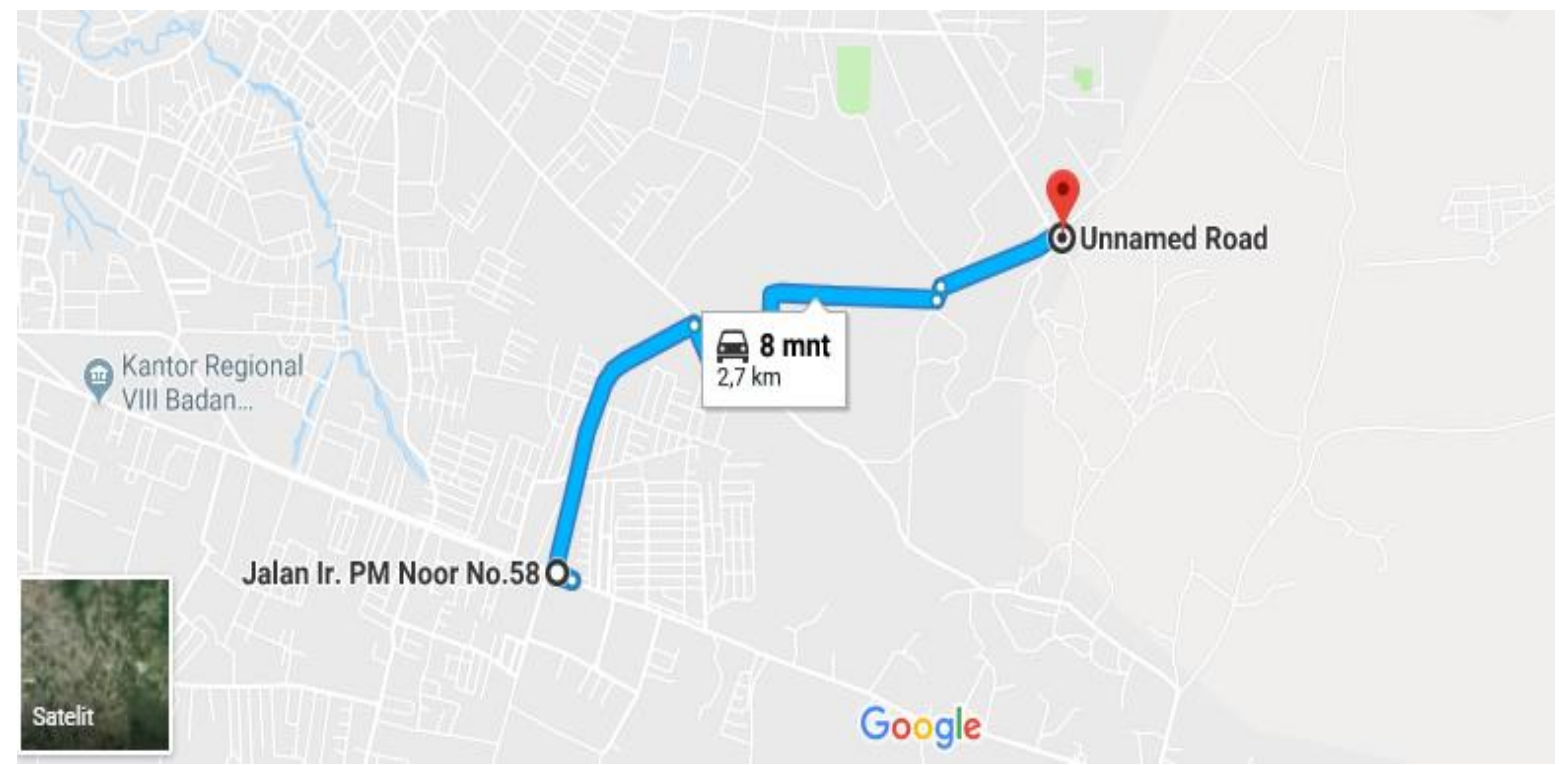

Gambar 6. Entry/Exit Kawasan Perkantoran Skenario 3 


\section{ANALISA DAMPAK LALU LINTAS TERHADAP RENCANA PENGEMBANGAN KAWASAN PERKANTORAN KOTA MARTAPURA \\ Bagus Ridhani}

Asumsi pergerakan penambahan arus menuju kawasan perkantoran yang digunakan yaitu apabila daerah asal berada di Banjarbaru, Banjarmasin dan Gambut akan melewati ruas jalan Alkah. Apabila daerah asal berada di Cindai Alus, Martapura, Sekumpul, Tanjung Rema, Indrasari, Sei.
Paring, Sei. Sipai dan Sei. Ulin akan melewati ruas jalan Sekumpul dan jalan Sekumpul Ujung (Indrasari). Asumsi pergerakan menuju kawasan perkantoran yang terjadi adalah pada waktu jam 08.00 WITA. Rekapitulasi hasil skenario dapat di lihat pada Tabel 2.

Tabel 2. Rekapitulasi Hasil Skenario

\begin{tabular}{|c|c|c|c|c|c|c|c|c|}
\hline \multirow[b]{2}{*}{ No } & \multirow[b]{2}{*}{ Ruas Jalan } & \multirow[b]{2}{*}{ Kondisi } & \multicolumn{2}{|c|}{ Skenario 1} & \multicolumn{2}{|c|}{ Skenario 2} & \multicolumn{2}{|c|}{ Skenario 3} \\
\hline & & & $\begin{array}{c}\text { Volume } \\
\text { (SMP/Jam) }\end{array}$ & $\begin{array}{l}\text { Pertumb } \\
\text { Lalin }\end{array}$ & $\begin{array}{c}\text { Volume } \\
\text { (SMP/Jam) }\end{array}$ & $\begin{array}{l}\text { Pertumb } \\
\text { Lalin }\end{array}$ & $\begin{array}{c}\text { Volume } \\
\text { (SMP/Jam) }\end{array}$ & $\begin{array}{l}\text { Pertumb } \\
\text { Lalin }\end{array}$ \\
\hline \multirow{4}{*}{1} & \multirow{4}{*}{$\begin{array}{l}\text { J1. A. Yani Km. } \\
39 \text { (Banjarbaru) }\end{array}$} & Eksisting & 3607 & & 3607 & & 3607 & \\
\hline & & Th. Ke-1 & 4189 & $16 \%$ & 4248 & $18 \%$ & 4043 & $12 \%$ \\
\hline & & Th. Ke-5 & 4871 & $35 \%$ & 4939 & $37 \%$ & 4740 & $31 \%$ \\
\hline & & Th. Ke-10 & 5754 & $60 \%$ & 5829 & $62 \%$ & 5639 & $56 \%$ \\
\hline \multirow{4}{*}{2} & \multirow{4}{*}{$\begin{array}{l}\text { J1. A. Yani Km. } \\
39 \text { (Martapura) }\end{array}$} & Eksisting & 3317 & & 3317 & & 3317 & \\
\hline & & Th. Ke-1 & 3743 & $13 \%$ & 3929 & $18 \%$ & 3743 & $13 \%$ \\
\hline & & Th. Ke-5 & 4387 & $32 \%$ & 4565 & $38 \%$ & 4387 & $32 \%$ \\
\hline & & Th. Ke-10 & 5211 & $57 \%$ & 5383 & $62 \%$ & 5211 & $57 \%$ \\
\hline \multirow{4}{*}{3} & \multirow{4}{*}{$\begin{array}{l}\text { Pusat } \\
\text { Perbelanjaan } \\
\text { Sekumpul }\end{array}$} & Eksisting & 879 & & 879 & & 879 & \\
\hline & & Th. Ke-1 & 962 & $9 \%$ & 962 & $9 \%$ & 962 & $9 \%$ \\
\hline & & Th. Ke-5 & 1131 & $29 \%$ & 1131 & $29 \%$ & 1131 & $29 \%$ \\
\hline & & Th. Ke-10 & 1348 & $53 \%$ & 1348 & $53 \%$ & 1348 & $53 \%$ \\
\hline \multirow{4}{*}{4} & \multirow{4}{*}{$\begin{array}{l}\text { J1. Sekumpul } \\
\text { (J1. A. Yani) }\end{array}$} & Eksisting & 4086 & & 4086 & & 4086 & \\
\hline & & Th. Ke-1 & 4815 & $18 \%$ & 4527 & $11 \%$ & 4567 & $12 \%$ \\
\hline & & Th. Ke-5 & 5603 & $37 \%$ & 5309 & $30 \%$ & 5356 & $31 \%$ \\
\hline & & Th. Ke-10 & 6617 & $62 \%$ & 6317 & $55 \%$ & 6374 & $56 \%$ \\
\hline \multirow{4}{*}{5} & \multirow{4}{*}{$\begin{array}{l}\text { Jl. Sekumpul } \\
\text { (Indrasari) }\end{array}$} & Eksisting & 1111 & & 1111 & & 1111 & \\
\hline & & Th. Ke-1 & 1579 & $42 \%$ & 1312 & $18 \%$ & 1433 & $29 \%$ \\
\hline & & Th. Ke-5 & 1796 & $62 \%$ & 1529 & $38 \%$ & 1665 & $50 \%$ \\
\hline & & Th. Ke-10 & 2071 & $86 \%$ & 1806 & $63 \%$ & 1956 & $76 \%$ \\
\hline & & Eksisting & 665 & & 665 & & 665 & \\
\hline & J. Tanjung & Th. Ke-1 & 750 & $13 \%$ & 750 & $13 \%$ & 809 & $22 \%$ \\
\hline 6 & Rema (J. & Th. Ke-5 & 876 & $32 \%$ & 876 & $32 \%$ & 944 & $42 \%$ \\
\hline & & Th. Ke-10 & 1037 & $56 \%$ & 1037 & $56 \%$ & 1112 & $67 \%$ \\
\hline & & Eksisting & 1817 & & 1817 & & 1817 & \\
\hline & J1. Tanjung & Th. Ke-1 & 1989 & $9 \%$ & 2011 & $11 \%$ & 1989 & $9 \%$ \\
\hline 7 & Rema (Pasar & Th. Ke-5 & 2337 & $29 \%$ & 2358 & $30 \%$ & 2337 & $29 \%$ \\
\hline & & Th. Ke-10 & 2787 & $53 \%$ & 2805 & $54 \%$ & 2787 & $53 \%$ \\
\hline & & Eksisting & 1674 & & 1674 & & 1674 & \\
\hline & $\begin{array}{l}\text { J. Sekumpul } \\
\text { Jiung }\end{array}$ & Th. Ke-1 & 2294 & $37 \%$ & 1996 & $19 \%$ & 2040 & $22 \%$ \\
\hline 8 & Ujung & Th. Ke-5 & 2629 & $57 \%$ & 2331 & $39 \%$ & 2380 & $42 \%$ \\
\hline & (Indrasari) & Th. Ke-10 & 3052 & $82 \%$ & 2756 & $65 \%$ & 2812 & $68 \%$ \\
\hline & & Eksisting & 737 & & 737 & & 737 & \\
\hline 0 & J. Sekumpul & Th. Ke-1 & 819 & $11 \%$ & 819 & $11 \%$ & 819 & $11 \%$ \\
\hline 9 & $\begin{array}{l}\text { Ujung (Sel. } \\
\text { Ulin) }\end{array}$ & Th. Ke-5 & 959 & $30 \%$ & 959 & $30 \%$ & 959 & $30 \%$ \\
\hline & & Th. Ke-10 & 1141 & $55 \%$ & 1141 & $55 \%$ & 1141 & $55 \%$ \\
\hline & & Eksisting & 1641 & & 1641 & & 1641 & \\
\hline & Pasar Martapura & Th. Ke-1 & 1797 & $9 \%$ & 2095 & $28 \%$ & 1797 & $9 \%$ \\
\hline 10 & (Jl. Sukaramai) & Th. Ke-5 & 2111 & $29 \%$ & 2409 & $47 \%$ & 2111 & $29 \%$ \\
\hline & & Th. Ke-10 & 2517 & $53 \%$ & 2813 & $71 \%$ & 2517 & $53 \%$ \\
\hline & & Eksisting & 964 & & 964 & & 964 & \\
\hline & & Th. Ke-1 & 1055 & $9 \%$ & 1353 & $40 \%$ & 1114 & $16 \%$ \\
\hline 11 & J. Barakat & Th. Ke-5 & 1240 & $29 \%$ & 1538 & $60 \%$ & 1308 & $36 \%$ \\
\hline & & Th. Ke-10 & 1478 & $53 \%$ & 1774 & $84 \%$ & 1553 & $61 \%$ \\
\hline & & Eksisting & 703 & & 703 & & 703 & \\
\hline & Jl. P. M. Noor & Th. Ke-1 & 769 & $9 \%$ & 769 & $9 \%$ & 968 & $38 \%$ \\
\hline 12 & (Banjarbaru) & Th. Ke-5 & 904 & $29 \%$ & 904 & $29 \%$ & 1087 & $55 \%$ \\
\hline & & Th. Ke-10 & 1078 & $53 \%$ & 1078 & $53 \%$ & 1242 & $77 \%$ \\
\hline & & Eksisting & 639 & & 639 & & 639 & \\
\hline & Jl. P. M. Noor & Th. Ke-1 & 699 & $9 \%$ & 699 & $9 \%$ & 699 & $9 \%$ \\
\hline 13 & (Karang Intan) & Th. Ke-5 & 822 & $29 \%$ & 822 & $29 \%$ & 822 & $29 \%$ \\
\hline & & Th. Ke-10 & 980 & $53 \%$ & 980 & $53 \%$ & 980 & $53 \%$ \\
\hline & & Eksisting & 788 & & 788 & & 788 & \\
\hline & & Th. Ke-1 & 863 & $9 \%$ & 863 & $9 \%$ & 1062 & $35 \%$ \\
\hline 14 & J. Alkah & Th. Ke-5 & 1014 & $29 \%$ & 1014 & $29 \%$ & 1197 & $52 \%$ \\
\hline & & Th. Ke-10 & 1209 & $53 \%$ & 1209 & $53 \%$ & 1373 & $74 \%$ \\
\hline
\end{tabular}

Apabila dilihat dari persentase pertumbuhan volume arus lalu lintas, urutan terbaik ke terburuk untuk mengurangi arus lalu lintas yang terjadi di ruas jalan Sekumpul dan ruas jalan Sekumpul Ujung adalah Skenario 2, 3 dan 1. Jelas di skenario 2 lebih 
sedikit dalam menghasilkan pertumbuhan arus lalu lintas pada ruas jalan Sekumpul dan Sekumpul Ujung. Namun hal tersebut berdampak pada ruas jalan Barakat dan Pasar Martapura (Jl. Sukaramai) dimana lokasi ruas jalan Barakat dan Pasar Martapura (Jl. Sukaramai) berdekatan dengan beberapa titik pusat kegiatan eksisting diantaranya dalah pusat kegiatan ekonomi (Pasar Martapura), rekreasi (Alun-alun Kota Martapura) serta permukiman penduduk yang relatif rapat. Selain itu setelah melewati jalan Sukaramai untuk menuju kawasan perkantoran adalah jalan melati dimana sepanjang ruas jalan melati merupakan kawasan permukiman penduduk sepanjang 7,70 $\mathrm{Km}$ sehingga apabila ingin menjadikan skenario 2 sebagai skenario penanganan terpilih akan memakan biaya pembebasan lahan yang cukup banyak serta akan mengganggu pusat kegiatan eksisting yang sudah ada terlebih dahulu.

Jika memilih skenario 3 dimana akses exit/entry kawasan perkantoran adalah ruas jalan Alkah, tidak ada pusat kegiatan yang memicu bangkitan pergerakan eksisting seperti pada skenario 2 dikarenakan pada lokasi tersebut masih relatif sepi dan jauh dari pusat kota. Tujuan dari membuat jalan Alkah sebagai entry/exit kawasan perkantoran adalah untuk mencegah arus lalu lintas dari luar kota Martapura menuju kawasan perkantoran sehingga tidak terhambat oleh pusat kegiatan eksisting yang sudah berjalan. Selain itu, apabila ingin melakukan pelebaran jalan pada ruas jalan Alkah tidak akan bermasalah dengan pembebasan lahan dikarenakan panjang ruas jalan Alkah relatif pendek yaitu 2,70 Km. Setelah menimbang berbagai faktor dari pertumbuhan volume arus lalu lintas serta kondisi lingkungan eksisting pada masingmasing skenario, maka dapat disimpulkan bahwa skenario 3 lebih direkomendasikan sebagai skenario penanganan untuk mengatasi dampak lalu lintas akibat pengembangan kawasan perkantoran Kota Martapura.

\section{KESIMPULAN}

Berdasarkan hasil analisis dan pengolahan data yang bisa diambil pada penelitian ini adalah:
1. Besar tarikan atau pergerakan perjalanan akibat kawasan perkantoran setelah beroperasi adalah sebesar 788 perjalanan baru atau 462 SMP/Jam yang bergerak menuju ke kawasan perkantoran.

2. Dari 14 ruas jalan yang ditinjau kinerja ruas jalan di sekitar kawasan pengembangan perkantoran dalam melayani arus lalu lintas pada kondisi eksisting, didapatkan bahwa ruas jalan yang memiliki tingkat pelayanan terburuk yaitu $D$ adalah ruas jalan Sekumpul (Jl. A. Yani), ruas Jalan Sekumpul Ujung (Indrasari) dan Pasar Martapura (Jalan Barakat) dengan masing-masing DS adalah 0,$85 ; 0,82$ dan 0,80 .

3. Prakiraan dampak lalu lintas yang dapat ditimbulkan pada jaringan jalan yang terpengaruh oleh kawasan perkantoran setelah beroperasi adalah dari kondisi eksisting dan masing-masing tahun tinjauan adalah kenaikan nilai $D S$ yang berkisar antara 9,48\% hingga 53,53\%. Peningkatan nilai $D S$ besar terjadi pada ruas jalan Sekumpul (Jl. A. Yani) dimana pada kondisi eksisting adalah sebesar 0,85 (ITP D) kemudian pada kondisi pasca konstruksi tahun pertama nilai $D S \quad 0,93$ (ITP E), pada kondisi 5 tahun pasca konstruksi nilai $D S \quad 1,09\left(\begin{array}{lll}\text { ITP } & F\end{array}\right)$ dan terakhir pada kondisi 10 tahun pasca konstruksi nilai $D S 1,30$ (ITP F).

4. Penanganan yang dapat diberikan untuk mengatasi masalah yang ditimbulkan untuk menjaga kelancaran arus lalu lintas pada jaringan jalan di sekitar kawasan perkantoran dari tiga Skenario yang digunakan Skenario 3 merupakan skenario penanganan yang di rekomendasi. Skenario 3 terpilih karena ruas jalan Alkah sebagai akses entry/exit kawasan perkantoran maka tidak akan menganggu pusat kegiatan eksisting yang sudah ada terlebih dahulu seperti pada Skenario 1 dan 2. Pertumbuhan lalu lintas yang terjadi di ruas jalan Sekumpul (Jl. A. Yani) yakni $12 \%$ hingga $56 \%$, ruas jalan Sekumpul (Indrasari) yakni $29 \%$ hingga $76 \%$ dan ruas jalan Sekumpul Ujung (Indrasari) yakni 22\%-68\%. 


\section{DAFTAR RUJUKAN}

Bupati Banjar Provinsi Kalimantan Selatan. 2015. Peraturan Daerah Kabupaten Banjar No. 2 Tahun 2015 tentang Analisis Dampak Lalu Lintas di Jalan.

Departemen Pekerjaan Umum. 2014. "Pedoman Analisis Dampak Lalu Lintas Jalan Akibat Pengembangan Kawasan di Perkotaan". Jakarta

Direktorat Pembangunan Jalan Perkotaan. 1997. "Manual Kapasitas Jalan Indonesia (MKJI) 1997. Direktorat Jenderal Bina Marga". Jakarta.

Josep S. 2013. “Analisis Dampak Lalulintas (ANDALALIN) Kawasan Kampus Universitas Sam Ratulangi." Jurnal Ilmiah Media Engineering. Vol. 3, No. 2, 133-143.

Kementerian Perhubungan. 2006. Peraturan Menteri Perhubungan No.KM 14 Tahun 2006 tentang Manajemen dan Rekayasa Lalulintas di Jalan

Lestari, F.A. 2014. Analisis Dampak Lalulintas Akibat Adanya Pusat Perbelanjaan di Kawasan Pasar Pagi Pangkalpinang Terhadap Kinerja Ruas Jalan. Jurnal Fropil Vol. 2 No. 1.

Marlock, E. K. 1985. Pengantar Teknik dan Perencanaan Transportasi. Terjemahan oleh Johan K. Jakarta: Erlangga.

Munawar A. 2009. "Analisis Dampak Lalulintas Pembangunan Pusat Perbelanjaan: Studi Kasus Plaza Ambarukmo." Jurnal Sains dan Teknologi Lingkungan. Vol. 1, No. 1.

Presiden Republik Indonesia. Peraturan Pemerintah No. 32 Tahun 2011 Tentang Manajemen dan Rekayasa, Analisis Dampak serta Manajemen Lalu Lintas.

Presiden Republik Indonesia. 2009. Undang-undang Nomor 22 Tahun 2009 Tentang Lalu Lintas dan Angkutan Jalan.

Rantung, T. 2015. “Analisa Dampak Lalu Lintas (Andalalin) Kawasan Lippo Plaza Kairagi Manado.” Jurnal Ilmiah Media Engineering. Vol. 5, No. 1, 315-327.
Subechi, W. A. 2007. Analisis Dampak Lalu-Lintas (Andalalin) Pada Pusat Perbelanjaan Yang Telah Beroperasi Ditinjau Dari Tarikan Perjalanan (Studi Kasus Pada Pacific Mall Tegal). Tesis Program Pasca Sarjana Magister Teknik Sipil Universitas Diponegoro.

Tambunan, H.F. 2016. Analisis Dampak Lalulintas Terhadap Pembangunan Hotel POP. Tesis Program Pasca Sarjana Magister Teknik Universitas Lampung. Bandar Lampung.

Tamin, O.Z. 2000. Perencanaan dan Pemodelan Transportasi. Penerbit Institut Teknologi Bandung, Bandung.

Wells, G. R. 1985. Rekayasa Lalu Lintas.

Diterjemahkan oleh Suwadjoko Warpani. Jakarta: Bhratara Karya Aksara.

Wiguna, A.P. 2012. “Analisis Dampak Lalulintas dari Universitas Esa Unggul Terhadap Ruas Jalan Arjuna Utara." Jurnal Planesa Vol. 3 No. 1.

Yugihartiman, M. (2012). Analisa Dampak Lalu Lintas [Power Point Slides]. Didapat dari: http://www.academia.edu/9911473/Pe doman_Andalalin (diakses 07 Juli 2017)

Yugihartiman, M. (2012). Diklat Andalalin Teknik Pelaksanaan Analisa Dampak Lalu Lintas [PDF Document]. Didapat dari:

http://www.scribd.com/doc/Analisis-

Dampak-Lalu-Lintas-2012 (diakses 07 Juli 2017)

Zuhdi,A.Y. 2017. Analisis Dampak Lalu Lintas Akibat Pembangunan Best Western Star Hotel Dan Star Apartement Semarang Terhadap Kinerja Jaringan Jalan Sekitar. Tesis Program Pasca Sarjana Magister Teknik Sipil, Universitas Diponegoro. 